\title{
Influência do uso tópico de proparacaína na reparação de defeito epitelial corneano
}

\author{
Effects of proparacaine on re-epithelialization of the cornea
}

Fabrício Witzel de Medeiros ${ }^{(1)}$

Milton Ruiz Alves ${ }^{(2)}$

Mônica Helena Teixeira da Silva ${ }^{(3)}$

Fernado Betty Cresta ${ }^{(4)}$

Newton Kara José ${ }^{(5)}$

\section{RESUMO}

Contexto: $\mathrm{O}$ uso tópico de soluções anestésicas é freqüientemente associado a efeitos tóxicos ao epitélio corneano. Por outro lado, seu uso tem sido proposto em algumas situações, especialmente após a ceratectomia fotorefrativa (PRK), um procedimento que envolve desepitelização corneana e que tem um periodo pós-operatório bastante doloroso.

Objetivo: Avaliar a influência do uso tópico de proparacaína nas concentrações a $\mathbf{0 , 0 5} \%$ e a $\mathbf{0 , 5} \%$ e de tampão fosfato (controle) na reparação de defeito epitelial corneano central.

Métodos: Um defeito de $6,0 \mathrm{~mm}$ de diâmetro foi realizado na córnea de uma população de coelhos. Os colírios contendo os anestésicos e o tampão fosfato foram instilados, uma gota a cada 30 minutos, durante 12 horas, por 2 dias. A avaliação da cicatrização do defeito epitelial foi feita com fotografias seriadas da área sem epitélio, corada com fluoresceína sódica e medida com o auxílio de um analisador de imagem computadorizado.

Resultados: A cicatrização corneana não apresentou diferença estatística entre os grupos comparados durante o estudo. A proparacaína nas diferentes concentrações não induziu alterações histopatológicas tais como: descontinuidade do epitélio, desorganização das camadas de colágeno ou presença de um infiltrado inflamatório intenso (o edema estrômico e o infiltrado inflamatório na região límbica foram discretos).

Conclusão: O uso tópico de proparacaína não retardou a reepitelização do defeito epitelial e não foi responsável pelo aparecimento de alterações histopatológicas importantes.

Palavras-chave: Proparacaína; Cicatrização epitelial.

\section{INTRODUÇÃO}

A técnica de ceratectomia fotorrefrativa (PRK), utilizando-se de um excimer laser para modificar a superfície anterior da córnea, vem sendo largamente empregada na correção da maioria dos erros refrativos. Com a aplicação do excimer laser remove-se parte do estroma e do epitélio corneano e, como estas estruturas são muito inervadas, freqüentemente ocorre dor considerável no pós-operatório. A dor pós-PRK é comumente tratada com o emprego de lente de contato hidrofílica terapêutica, de agentes antinflamatórios não esteróides e de analgésicos por via oral ${ }^{1-2}$. 
Recentemente, VERMA et $\mathrm{al}^{3}$ realizaram um estudo clínico, aleatório, prospectivo, para avaliar o papel de anestésicos tópicos no controle da dor pós-operatória de pacientes submetidos a PRK. Os autores concluíram que para reduzir efetivamente a dor pós-PRK o anestésico tópico (tetracaína a 1,0\%) deveria ser instilado a cada 30 minutos durante as 48 horas iniciais. Não foi observado retardo da reepitelização corneana e/ou complicações com o uso restrito do anestésico aos 2 dias iniciais. A tetracaína reduz a sensibilidade táctil corneana, que é um importante mecanismo de proteção ${ }^{4}$, e é tóxica para a córnea quando utilizada por tempo prolongado e repetidamente ${ }^{5-6}$. A proparacaína é um anestésico menos tóxico para a córnea que a tetracaína, mas o seu uso crônico e repetido também tem sido associado com complicações corneanas graves ${ }^{5-7}$.

Com o emprego de concentrações mais diluídas de proparacaína tem se procurado reduzir ou eliminar o seu potencial de toxicidade corneana ${ }^{8-9}$. MAURICE \& SINGH ${ }^{8}$ instilaram proparacaína a $0,3 \%$ em olhos de coelhos por uma semana e não constataram ulceração do epitélio corneano. BISLA \& TANELIAN ${ }^{9}$ especularam que a instilação de anestésico diluído poderia prover analgesia corneana segura. SHAHINIAN et al ${ }^{10}$ demonstraram em seres humanos que o uso tópico de proparacaína a $0,05 \%$ induziu analgesia e não anestesia corneana, não desencadeando toxicicidade epitelial corneana. Os autores concluíram que a sua utilização na primeira semana pós-PRK era segura.

O presente trabalho tem como objetivo avaliar a influência do uso tópico de proparacaína, nas concentrações de $0,5 \%$ e $0,05 \%$, na reparação de defeito epitelial corneano central, em coelhos.

\section{MATERIAL E MÉTODOS}

Utilizaram-se 10 coelhos albinos da raça Nova Zelândia, espécie Oryctolagus cuniculus, pesando entre 1800 e 2500 g, examinados inicialmente com lâmpada de fenda para excluir anormalidades oculares. Os animais tiveram para a identificação, suas orelhas direitas numeradas de 1 a 10, com caneta hidrográfica. Os animais foram tratados de acordo com as normas recomendadas pelo Colégio Brasileiro de Experimentação Animal.

Os animais foram anestesiados com injeção intramuscular de uma mistura de cloridrato de cetamina (Ketalar ${ }^{\circledR}$ ), na dose de $50 \mathrm{mg} / \mathrm{Kg}$ de peso, e de xilazina (Rompum ${ }^{\circledR}$ a $2 \%$ ), na dose de $5 \mathrm{mg} / \mathrm{kg}$ de peso. Após a instilação de 2 gotas de tetracaína a $0,5 \%$, realizaram-se em todos os olhos defeitos superficiais na porção central da córnea. A demarcação da área a ter o epitélio removido foi feita, sob magnificação, com trépano de 6,0 $\mathrm{mm}$ de diâmetro, de fabricação Storz. O trépano foi mantido em posição, enquanto o epitélio a ser removido era tocado por 30 segundos por uma zaragatoa embebida em álcool etílico a $45 \%$ e, posteriormente, secado e finalmente irrigado com solução de cloreto de sódio a $0,9 \%$. O epitélio que ao final ainda persistia na área demarcada era removido com bisturi lâmina 15. A eficácia da ablação epitelial foi controlada com a instilação de 2 gotas de fluoresceína sódica a $2 \%{ }^{11}$.

Imediatamente após a realização do defeito epitelial os olhos dos animais foram divididos em três grupos (A, B e C), usando-se para casualização uma tabela de números aleatórios. O grupo A (controle) foi composto por 7 olhos que receberam a instilação de colírio contendo tampão fosfato sem preservativo. $\mathrm{O}$ grupo B foi composto por 7 olhos que receberam colírio de proparacaína a $0,5 \%$ sem preservativo. $\mathrm{O}$ grupo $\mathrm{C}$ foi composto por 6 olhos que receberam colírio de proparacaína a $0,05 \%$ sem preservativo. Os colírios foram manipulados por farmacêutico (Farmácia Ophthalmos, São Paulo). Nos dois primeiros dias de pós-operatório, os anestésicos e a solução controle foram instilados a cada 30 minutos durante o período de 12 horas. Antes da instilação das drogas, as pálpebras dos coelhos foram levantadas de forma que toda a solução colocada permanecesse dentro da bolsa formada e depois elas foram movimentadas para maior distribuição e absorção, minimizando, assim, a perda da solução.

Para a avaliação quantitativa do epitélio em regeneração a área corneana sem epitélio foi corada com fluoresceína sódica a $2 \%$ e fotografada com um sistema de macrofotografia (lente macro de $100 \mathrm{~mm}$-Asahi Pentax, foco de $45 \mathrm{~cm}$, flash eletrônico Toshiba-modelo 8184 com filtro Wratten Kodak 47B e filme Kodacolor Gold 100ASA) imediatamente após a realização do defeito epitelial e posteriormente a cada 12 horas encerrando-se com a cicatrização da lesão epitelial. Após a identificação na fotografia, a área sem epitélio foi medida com o auxílio de uma câmara de vídeo acoplada a um sistema analisador de imagem (JAVA 1,4). Cada fotografia foi projetada pela câmara de vídeo e imobilizada no monitor, permitindo contornar com o "mouse" a área corada pela fluoresceína. Ao final obtinha-se diretamente do sistema, o valor da área desprovida de epitélio, em milímetros quadrados, na fotografia (AF-área do defeito epitelial obtida da fotografia). Para a obtenção do valor do raio da superfície corneana de ablação epitelial (r), a AF foi tratada como círculo equivalente e o seu raio de curvatura ( $\mathbf{r}^{\prime}$ ) foi calculado. Foram assumidas como esféricas as curvaturas central e paracentral da córnea de coelho e considerou-se para efeito de cálculo como sendo 7,2 $\mathrm{mm}$ o valor de seu raio de curvatura $(\mathbf{R})^{12}$. A área $\mathbf{A S}$ foi calculada como: $\mathbf{A S}=\boldsymbol{\pi} \mathbf{R h}(\mathrm{I})$, onde $(\mathrm{h})$ corresponde a profundidade sagital da esfera corneana considerada, sendo seu valor dado pela equação ${ }^{13}$ :

$$
\mathbf{h}=\mathbf{R}-\sqrt{\mathbf{R}^{2}-\mathbf{r}^{\mathbf{2}}}
$$

Substituindo o valor de $\mathbf{h}$ na equação ( I ), obtém-se o valor de AS:

\section{$\mathrm{AS}=2 \pi \mathbf{R}\left(\mathbf{R}-\sqrt{\mathbf{R}^{2}-\mathbf{r}^{\mathbf{2}}}\right)$}

Finalmente, a partir dos valores de AS calculam-se os valores individuais de $\mathbf{r}$.

$$
\mathbf{A S}=\pi \mathbf{r}^{2}, \text { e } \mathbf{r}=\sqrt{\mathrm{As} / \boldsymbol{\pi}}
$$


Para o estudo da reparação do defeito epitelial, empregouse um modelo de análise baseado na diminuição do raio da ferida no tempo.

Após 24 horas da completa reepitelização do defeito epitelial 5 animais foram sacrificados com injeção na veia marginal da orelha, contendo $65 \mathrm{mg} / \mathrm{Kg}$ de peso de pentobarbital sódico (Hypnol a 3\%). Foram retiradas 4 córneas de olhos controle, 3 de olhos tratados com proparacaína a $0,05 \%$ e outras 3 de olhos que receberam proparacaína a $0,05 \%$. Todas as córneas foram transferidas para frascos individuais numerados contendo formol tamponado a $10 \%$ para posterior inclusão em parafina. Foram obtidos cortes histológicos de 5 micrômetros de espessura dos tecidos incluídos em parafina, corados com hematoxilina-eosina, e foram observados os seguintes parâmetros: epitélio corneano - continuidade da camada de células epiteliais com o estroma adjacente, atipia celular (hipercromasia e/ou polimorfismo nuclear) e número de camadas; estroma - alterações do colágeno, caracterizadas pela presença de uma faixa de homogeneização de suas lamelas no estroma corneano e presença de infiltrado inflamatório. A avaliação histopatológica das lâminas foi realizada por patologista que desconhecia de que animal ou grupo provinha o material de estudo.

Os resultados da análise quantitativa do epitélio em regeneração (curva de cicatrização epitelial) foram avaliados empregado-se as provas de Mann-Whitney (U) para comparações entre dois grupos e a de Kruskal- Wallis (H) para comparação entre os três grupos.

\section{RESULTADOS}

Os valores médios dos raios da superfície corneana sem epitélio com o tempo, entre dois diferentes tratamentos, encontram-se nas tabelas 1 a 5 . O gráfico da curva de cicatrização (raio da superfície de desepitelização versus tempo) acompanha as tabelas.

No estudo histopatológico das córneas dos olhos-controle do grupo A, evidenciou-se córnea com células epiteliais ordenadamente dispostas, com as camadas obedecendo maturação natural, continuidade das camadas epiteliais com cerca de 3 a 4 camadas, disposição paralela das lamelas colágeno, sem alterações aparentes de celularidade estrômica, ausência de edema e de infiltrado inflamatório. Nos olhos dos coelhos dos

\begin{tabular}{|c|c|c|c|c|c|c|}
\hline Tratamento & VM & $\pm \mathrm{DP}$ & MED & Min & Max & $\mathbf{N}$ \\
\hline CONTROLE & 2,84 & 0,30 & 2,78 & 2,36 & 3,26 & 7 \\
\hline PPC $0,5 \%$ & 2,88 & 0,28 & 2,89 & 2,53 & 3,25 & 7 \\
\hline \multirow[t]{2}{*}{ PPC 0,05\% } & 2,92 & 0,31 & 2,98 & 2,37 & 3,25 & 6 \\
\hline & & $\mathrm{H}=0,58$ & & $=0,74$ & & \\
\hline
\end{tabular}

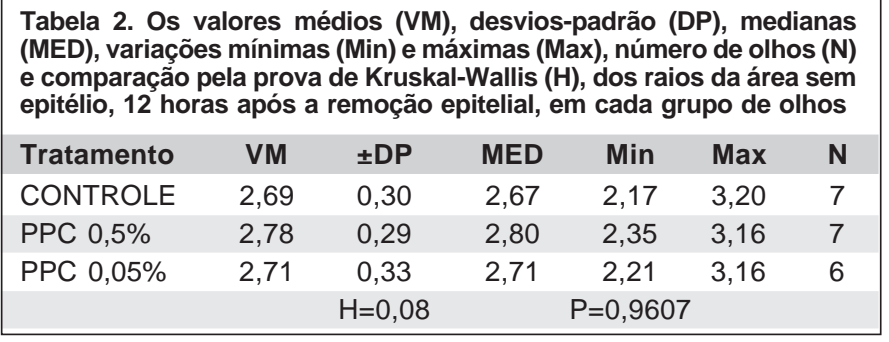

\begin{tabular}{|c|c|c|c|c|c|c|}
\hline Tratamento & VM & $\pm \mathrm{DP}$ & MED & Min & Max & $\mathbf{N}$ \\
\hline CONTROLE & 2,08 & 0,23 & 2,15 & 1,62 & 2,34 & 7 \\
\hline PPC $0,5 \%$ & 2,38 & 0,34 & 2,34 & 1,96 & 2,97 & 7 \\
\hline \multirow[t]{2}{*}{ PPC $0,05 \%$} & 2,18 & 0,49 & 2,04 & 1,52 & 2,90 & 6 \\
\hline & & $\mathrm{H}=2,15$ & & $=0,34$ & & \\
\hline
\end{tabular}

\begin{tabular}{|c|c|c|c|c|c|c|}
\hline Tratamento & VM & $\pm \mathrm{DP}$ & MED & Min & Max & $\mathbf{N}$ \\
\hline CONTROLE & 1,42 & 0,33 & 1,47 & 0,81 & 1,79 & 7 \\
\hline PPC 0,5\% & 1,97 & 0,54 & 2,00 & 1,21 & 2,74 & 7 \\
\hline \multirow[t]{2}{*}{ PPC $0,05 \%$} & 1,59 & 0,56 & 1,58 & 0,77 & 2,46 & 6 \\
\hline & & $H=4,02$ & \multicolumn{3}{|c|}{$P=0,1341$} & \\
\hline
\end{tabular}

\begin{tabular}{|c|c|c|c|c|c|c|}
\hline Tratamento & VM & $\pm \mathrm{DP}$ & MED & Min & Max & $\mathbf{N}$ \\
\hline CONTROLE & 0,80 & 0,55 & 0,74 & 0,23 & 1,50 & 4 \\
\hline \multirow[t]{2}{*}{ PPC $0,5 \%$} & 1,09 & 0,45 & 0,81 & 0,71 & 1,64 & 5 \\
\hline & & $\mathrm{U}=6,0$ & & $=0,327$ & & \\
\hline
\end{tabular}

lotes B e C evidenciou-se córnea em aspecto histológico semelhante ao apresentado pelos animais do lote A, edema estrômico discreto e presença de infiltrado inflamatório discreto na região límbica (polimorfonuclear).

\section{COMENTÁRIOS}

As opções terapêuticas disponíveis para o alívio da dor pós-PRK são inadequadas ou inaceitáveis para muitos pacientes ${ }^{10}$. Além disso, freqüentemente a dor persiste nos primeiros 4 dias após a cirurgia. Para o controle da dor durante esse período, é necessário que o anestésico tópico seja instilado repetidamente e como pode induzir complicações corneanas 


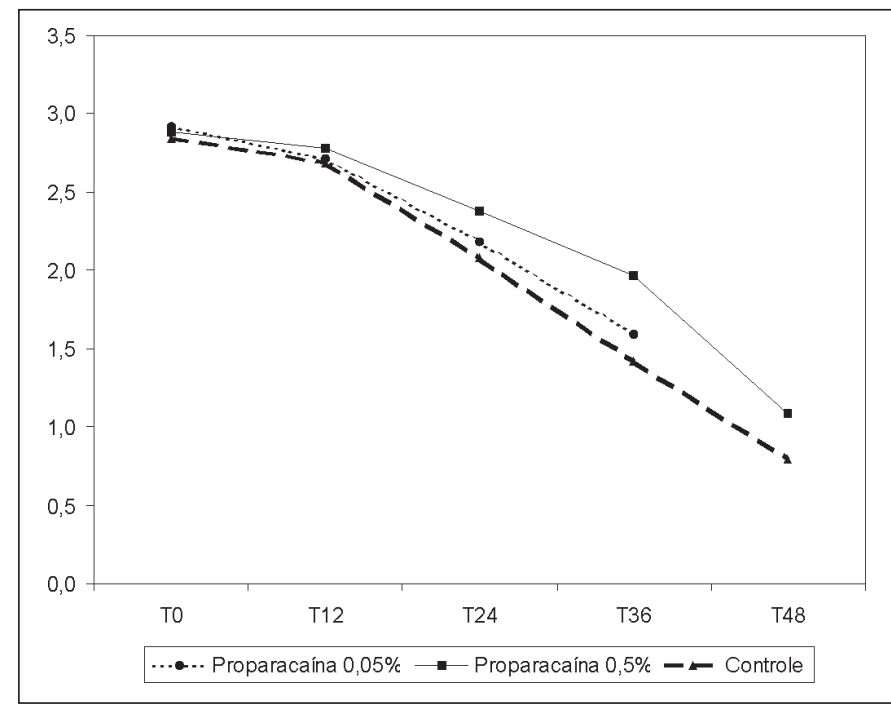

Fig. 1 - Representação gráfica comparativa dos valores médios dos raios das áreas da superfície corneana sem epitélio, com o tempo, entre os olhos tratados com tampão fosfato e os medicados com proparacaína a $0,5 \%$ e a $0,05 \%$.

graves, impõe-se a realização de estudos voltados para a avaliação de sua segurança.

O uso tópico de anestésico reduz a sensibilidade táctil corneana diminuindo reflexos de proteção ocular, tornando a córnea mais vulnerável a agressões ${ }^{4}$. A proparacaína apresenta baixa toxicidade corneana, característica que a torna um agente anestésico muito utilizado em oftalmologia ${ }^{6}$. O uso de concentrações mais diluídas de anestésico (proparacaína a $0,05 \%$ ) além de não ter efeito anestésico parece não apresentar toxicidade epitelial corneana relevante ${ }^{10}$.

A avaliação da reparação do epitélio corneano, após trauma, constitui modelo de experimentação útil para o estudo dos mecanismos e influências de diversos fatores na cicatrização, inclusive o de ação de drogas, como os anestésicos tópicos. Defeitos epiteliais centrais cicatrizam por deslizamento celular seguido por uma onda de mitose que empurra as células da periferia para o centro ${ }^{13}$. Neste estudo, os defeitos epiteliais corneanos desapareceram dentro de 48-60 horas. A análise dos resultados mostra que o uso tópico de proparacaína, nas concentrações de $0,05 \%$ e $0,5 \%$, não induziu alterações histopatológicas significativas e não influenciou na reparação de defeitos epiteliais corneanos em coelhos.

\section{SUMMARY}

Context: The topical use of anesthetic solutions is usually associated with toxic effects on the corneal epithelium. On the other hand, their use has been proposed for some situations, especially after photorefractive keratectomy
(PRK), a procedure that involves corneal scraping and has a very painful postoperative period.

Purpose: To evaluate the influence of the topical use of proparacaine $(0.05 \%$ and $0.5 \%)$ and phosphate buffer on the epithelial healing of corneal central wounds.

Methods: A central epithelial corneal wound of a $6.0 \mathrm{~mm}$ diameter was performed in rabbits. Proparacaine and buffer were instilled every 30 minutes for 12 hours a day for 2 days. Epithelial regeneration was assessed through sequential photographs of the defective area stained with sodium fluorescein and the quantification of this area was performed using a computerized image analyzer.

Results: There were no statistical differences in the corneal healing between the compared groups during the study. Proparacaine in those concentrations didn't induce histopathological abnormalities such as discontinuity of the epithelium, disorganization of collagen layers or polymorphonuclear infiltration (the stromic edema and the limbic inflammatory infiltrates were not important).

Conclusion: Topical use of proparacaine didn't delay reepithelialization of the defective area and was not responsible for important histopathological abnormalites.

Keywords: Proparacaine; Corneal wound healing.

\section{REFERÊNCIAS BIBLIOGRÁFICAS}

1. Cherry PMH, Tutton MK, Adhikary H. The treatment of pain following photorefractive keratectomy. J Refract Corneal Surg 1994;10:222-5.

2. Tutton MK, Cherry PMH, Sunder RAJ. Efficacy and safety of topical diclofenac in reducing ocular pain after excimer laser photorefractive keratectomy. J Refract Corneal Surg 1996;22:536-41.

3. Verma S, Corbett MC, Marshall J. A prospective, randomized, double-masked trial to evaluate the role of topical anesthetics in controlling pain after photorefractive keratectomy. Ophthalmology 1995;102:1918-24.

4. Peyman GA, Rahin MH, Fernandes MI. Effects of morfine on corneal sensitivity and epithelial wound healing: implications for topical ophthalmic analgesia. Br J Ophthalmol 1994;78:138-41.

5. Rosenwasser GOD, Holland S, Pflugfelder SC. Topical anesthetic abuse. Ophthalmology 1990;97:967-72.

6. Marcondes AM. Anestésicos tópicos. In Vita Sobrinho, JB: Farmacologia \& Terapêutica ocular. Rio de Janeiro, Cultura Médica, 1999;29-34.

7. Epstein DL, Paton D. Keratitis from the misuse of topical anesthetics. N Engl J Med 1968;279:396-9.

8. Maurice DM, Singh T. The absence of corneal toxicity oflow-level topical anesthesia. Am J Ophthalmol 1985;99:691-6.

9. Bisla K, Tanelian DL. Concentration-dependent lidocaine on corneal epithelial wound healing. Invest Ophthalmol Vis Sci 1992;33:3029-33.

10. Shahinian Jr. L, Jain S, Jager RD, Lin DTC, Sanislo SS, Miller JF. Dilute topical proparacaine for pain relief after photorefractive keratectomy. Ophthalmology 1997;104:1327-32.

11. Alves MR, Mattar DB, Milani JAA, Silva MHT. Estudo planejado da reparação do epitélio corneano após trauma planejado, em coelhos. Arq Bras Oftalmol 1994;57:134-36.

12. Prince JH. The rabbit in eye research. Springfield, Charles C. Thomas, 1965; 87-8.

13. Hanna C, O'Brien JE. Cell production and migration in the epithelial layer of the cornea. Arch Ophthalmol 1960;64:536-9. 